Biol. Proced. Online 2003;5(1): 197-203.

\title{
Development of a new protocol for 2-day generation of mature dendritic cells from human monocytes
}

\author{
Bianca Obermaier ${ }^{1}$, Marc Dauer $^{2}$, Jan Herten ${ }^{1}$, Katharina Schad ${ }^{1}$, Stefan Endres ${ }^{1}$, Andreas \\ Eigler ${ }^{3}$
}

'Division of Clinical Pharmacology, Medizinische Klinik Innenstadt, University of Munich, Ziemssenstr. 1, 80336 Munich, Germany. B.O. and M.D. contributed equally to this manuscript.

2Division of Clinical Pharmacology and Section of Gastroenterology, Medizinische Klinik Innenstadt, University of Munich, Ziemssenstr. 1, 80336 Munich, Germany.

3To whom correspondence should be addressed: Dr. Andreas Eigler, Abteilung fuer Klinische Pharmakologie, Medizinische Klinik Innenstadt, University of Munich, Ziemssenstr.1, 80336 Munich, Germany. Phone: 49-89-51602291; Fax: 49-89-51604576; E-mail: Andreas.Eigler@med.uni-muenchen.de

Submitted: August 18, 2003; Revised: September 21, 2003; Accepted: September 22, 2003; Published: October 24, 2003

Indexing terms: Monocytes; Dendritic cells; Antigen presenting cells; Vaccination; Cell differentiation.

Abbreviations: DC, dendritic cell; moDC, monocyte-derived DC; PBMC, peripheral blood mononuclear cells; CD40L, soluble CD40 ligand-trimer.

\begin{abstract}
We developed a new 2-day protocol for the generation of dendritic cells (DCs) from human monocytes in vitro. First, we demonstrated that 24 hours of culture with GM-CSF and IL-4 are sufficient to generate immature DCs capable of antigen uptake. We then compared two different strategies for DC maturation: proinflammatory mediators were either added together with GM-CSF and IL-4 from the beginning of cell culture or added after 24 hours of differentiation with GM-CSF and IL-4. After 48 hours of total culture period, expression of activation markers was more pronounced in cells generated by the 2 -step differentiation and activation method. Our new protocol for 2-day DC differentiation reduces labor, cost and time and also reliably renders high numbers of mature and viable DCs.
\end{abstract}

\section{INTRODUCTION}

Dendritic cells (DCs) are highly specialized antigen presenting cells that possess the unique ability to initiate primary immune responses. Immature DCs reside in peripheral tissues where they take up and process antigen for presentation on MHC molecules (1). In response to inflammatory, microbial or $\mathrm{T}$-cell derived stimuli, maturation of DCs is induced. Upon maturation, they upregulate $\mathrm{MHC}$ molecules as well as various adhesion and costimulatory molecules and thus become potent stimulators of naïve $\mathrm{T}$ cells $(2,3)$.

Circulating DCs in human blood are rare $(<1 \%$ of human PBMC) and difficult to maintain in culture. Therefore, monocytes are used as progenitors for the in vitro generation of DCs $(4,5)$. Commonly, monocytes are cultured with GM-CSF and IL-4 for 5 to 7 days followed by stimulation for another 2 to 3 days (moDCs).

C2003. Biological Procedures Online. Published in Biological Procedures Online under license from the author(s). Copying, printing, redistribution and storage permitted. 
There is increasing evidence that the time span required for DC differentiation in vivo may be shorter. It has been shown that a subpopulation of monocytes differentiated into mature DCs upon reverse transmigration across an endothelial barrier within 48 hours (6). Moreover, GM-CSF-cultured monocytes activated with calcium ionophore or CD40L rapidly express mature DC surface markers $(7,8)$. Santini et al. showed that culture of GMCSF-treated monocytes with type I Interferon induced DC maturation within 3 days without the need for further stimulation (15). These cells upregulated the costimulatory molecules CD80, CD86 and CD40 and the antigen-presenting molecule MHCII, but only moderately expressed the mature DC surface marker CD83.

The aim of this study was to develop a protocol of accelerated DC maturation in vitro. We compared two different approaches to generate dendritic cells from monocytes within 48 hours trying to reflect a potential in vivo process of DC differentiation. Furthermore, we identified an optimal combination of proinflammatory mediators for stimulation and tested the endocytic capacity of DCs generated according to the new protocol. Our results show that fully functional dendritic cells can be generated within 48 hours from monocytes. This protocol represents a cost-effective and reliable alternative to the traditional standard protocols.

\section{MATERIALS AND METHODS}

\section{Reagents and ELISA kits}

Recombinant cytokines: GM-CSF was purchased from Novartis (Basel, Switzerland), IL-4 from Promega (Madison, WI), TNF- $\alpha$ from R\&D Systems (Wiesbaden, Germany) and IL-6 from Amersham (Buckinghamshire, UK); IL-1 $\beta$ was obtained from Strathmann Biotech (Hannover, Germany). PGE 2 and FITCdextran were purchased from Sigma-Aldrich (Steinheim, Germany). Soluble CD40 ligand-trimer (CD40L) was a generous gift of Immunex, Seattle, WA. Total IL-12 was determined using an assay that detects both IL-12 (p40) and IL-12 (p70) (Bender Med Systems, Vienna, Austria). IL-12 (p70) and IL-12 (p40) were measured separately using OptEIA human IL-12 (p70) or IL-12 (p40) set form Pharmingen (San Diego, CA).

\section{Media}

All cultures of human PBMC were maintained in RPMI 1640 medium (Biochrom, Berlin, Germany) supplemented with 2\% human $\mathrm{AB}$ serum (BioWhittaker, Walkersville, MD), $2 \mathrm{mM} \mathrm{L-}$ glutamine (Life Technologies, Paisley, Scotland), $50 \mathrm{U} / \mathrm{ml}$ penicillin and $50 \mu \mathrm{g} / \mathrm{ml}$ streptomycin (Sigma, Munich, Germany), hereafter referred to as complete medium.

\section{Isolation and culture of cells (see Protocol $1 \& 2$ )}

In short, PBMC were isolated from peripheral blood of healthy donors by Ficoll-hypaque gradient centrifugation. Monocytes were purified either by using the MACS CD14 isolation kit (Miltenyi Biotec, Bergisch Gladbach, Germany) or by collecting the plastic adherent fraction of PBMC as described (9). Subsequently, monocytes were cultured in six-well plates $(0.5$ to $1.5 \times 10^{6}$ cells $/ \mathrm{ml}$ ) in fresh complete medium supplemented with $1000 \mathrm{U} / \mathrm{ml} \mathrm{GM}-\mathrm{CSF}$ and $500 \mathrm{U} / \mathrm{ml}$ IL-4. To generate standard monocyte-derived DCs (moDCs), cells were cultured for 6 days and subsequently incubated with a combination of proinflammatory mediators for 24 hours $(1000 \mathrm{U} / \mathrm{ml}$ TNF- $\alpha, 10$ $\mathrm{ng} / \mathrm{ml} \mathrm{IL}-1 \beta, 10 \mathrm{ng} / \mathrm{ml}$ IL-6 plus $\left.1 \mu \mathrm{M} \mathrm{PGE}_{2}\right)$. Alternatively, two different approaches were made to accelerate DC maturation: monocytes were cultured with GM-CSF $(1000 \mathrm{U} / \mathrm{ml})$ and IL-4 $(500 \mathrm{U} / \mathrm{ml})$. The proinflammatory mediators were either added at the initiation of culture or after 24 hours of incubation. In both cases, cells were harvested after a total culture period of 48 hours.

\section{Flow cytometry and monoclonal antibodies}

The following monoclonal antibodies were used for FACS analysis: TÜ39 (anti-HLA DR, DP, DQ, FITC-conjugated), L307.4 (anti-CD80, PE-conjugated), 2331/FUN-1 (anti-CD86, APC-conjugated), HB15e (anti-CD83, FITC-conjugated) and M5E2 (anti-CD14, APC-conjugated).

\section{Measurement of FITC-dextran uptake}

Endocytic activity was assessed by incubating cells for 2 hours with FITC-dextran $(0.5 \mathrm{mg} / \mathrm{ml})$ at $37^{\circ} \mathrm{C}$. Cells were washed extensively with PBS and FITC-dextran uptake was quantified as mean fluorescence intensity (MFI) (nonspecific FITC signal was assessed by incubating cells on ice).

\section{Statistical analysis}

Data are expressed as means \pm SEM. Statistical significance was determined using the paired two-tailed Student's $t$ test. Differences were considered statistically significant for $\mathrm{p}<0.05$. Significance is presented for individual experiments (asterisks in figures). Statistical analysis was performed using Stat-View 4.51 software (Abacus Concepts, Calabasas, CA, USA).

\section{RESULTS AND DISCUSSION}

\section{Development of a new method of accelerated DC maturation}

Monocytes were isolated from PBMC by using the MACS CD14 isolation kit or by collecting the plastic adherent fraction of PBMC (Protocol 1). Monocytes were either cultured with GMCSF and IL-4 for 48 hours (immature DCs) (Fig. 1, top), or with GM-CSF and IL-4 plus proinflammatory mediators (TNF- $\alpha$, IL$1 \beta$, IL-6 plus PGE $_{2}$ ) for 48 hours (Fig. 1, middle), or cultured for 24 hours with GM-CSF and IL-4 and subsequently stimulated with proinflammatory mediators for another 24 hours (Fig. 1, 
bottom). Monocytes cultured with GM-CSF and proinflammatory mediators only (without IL-4) served as a control group.

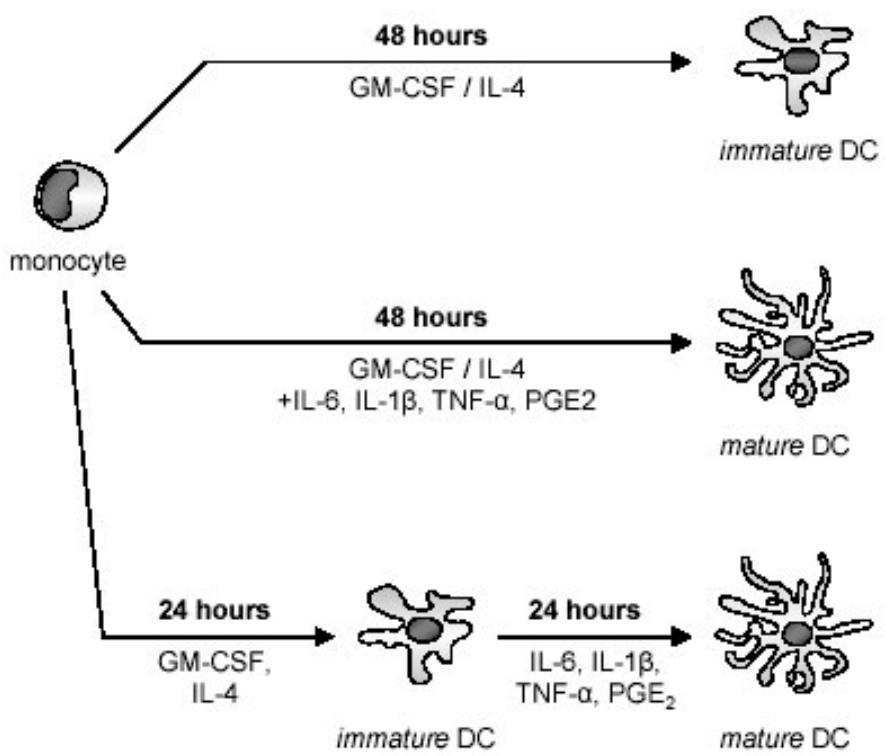

Fig. 1: Two different strategies were tested to identify an optimal protocol for the generation of dendritic cells from monocytes within 48 hours. Monocytes were cultured with GM-CSF and IL-4 to generate immature DCs (top). To accelerate DC-maturation, monocytes were either stimulated with proinflammatory mediators from the initiation of culture (middle) or they were stimulated with the proinflammatory mediators after 24 hours of culture with GM-CSF/IL-4 (bottom). All cell populations were harvested after a total culture period of 48 hours to assess phenotype and function.

Cells cultured with GM-CSF and IL-4 only downregulated CD 14, expressed moderate levels of CD86 and MHCII and stayed CD83 negative corresponding to an immature DC immunophenotype. To determine the minimal time span required for DC maturation, cells cultured with GM-CSF and IL4 plus proinflammatory mediators were harvested and tested for the expression of surface markers at various time points: after 12 , 24, 48 and 72 hours of total culture period. After 48 hours, we noted changes typical for mature DCs in stimulated cells: cells showed decrease of the monocytic surface marker CD 14 and increase of mature DC surface markers (CD83, CD86, MHCII). We could not observe further changes in the expression of surface markers after 72 hours of culture in the presence of cytokines. Therefore, we concluded that after 48 hours of total culture period, cells had completed DC differentiation (data not shown).

As expected, cells did not display DC characteristics but showed a macrophage-like phenotype with high levels of CD 14 and low levels of CD1a if cultured in the absence of IL-4 (data not shown) (10).

Cells harvested from cultures where the two-step differentiation and activation protocol was used showed significantly higher expression of CD83 and 3-fold increase in secretion of total IL12 (this trend did not reach statistical significance due to the large differences in maximal levels of IL-12 detected) compared to cells cultured with GM-CSF and IL-4 plus proinflammatory mediators from the beginning of cell culture (Fig. 2). IL-12 (p40)measurement correlated with measurement of total IL-12 (data not shown). Bioactive IL-12 (p70) could not be detected in any of the supernatants. Only after additional stimulation of DCs with soluble CD40Ligand and IFN- $\gamma$ could production of IL-12 (p70) be observed (14).

In summary, these experiments demonstrate that fully mature dendritic cells can be derived from monocytes within 48 hours. The sequential activation and differentiation strategy proved to be superior to activation from the beginning of cell culture. DCs generated with the two-step method will further be referred to as FastDC (Protocol 2).

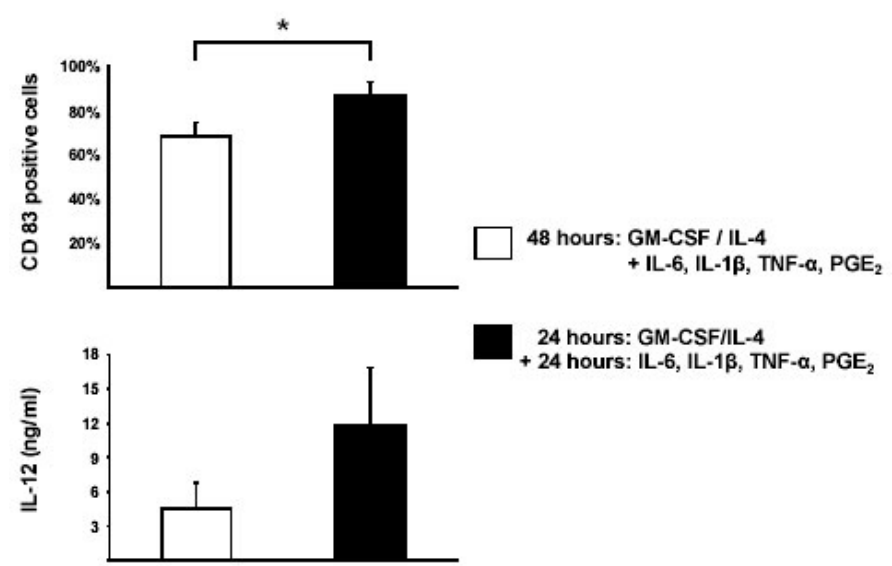

Fig. 2: Dendritic cells generated according to a 2-step protocol of differentiation and activation show significantly higher expression of the surface marker CD83 and secrete higher levels of IL-12. Monocytes cultured with GM-CSF/IL-4 were either stimulated with proinflammatory mediators at the initiation of culture or after 24 hours of culture. After 48 hours of total culture period cells were harvested. Expression of the mature DC surface marker CD83 was determined by FACS (top) and culture supernatants were harvested for measurement of total IL-12 (IL-12 (p40) and IL-12 (p70), bottom). Data represent means \pm SEM of three experiments with different donors.

\section{Comparison of FastDC with standard moDCs}

Next, we compared expression of activation markers on FastDC with those on standard monocyte-derived DCs (moDCs). Monocytes were either cultured with GM-CSF plus IL-4 for 48 hours or stimulated with proinflammatory mediators for the last 24 hours of culture. Alternatively, monocytes were cultured with GM-CSF plus IL-4 for five days and stimulated for another 2 days (moDCs). Cell morphology was compared by light microscopy. Cells incubated with GM-CSF plus IL-4 alone were similar to the initial monocyte population. 


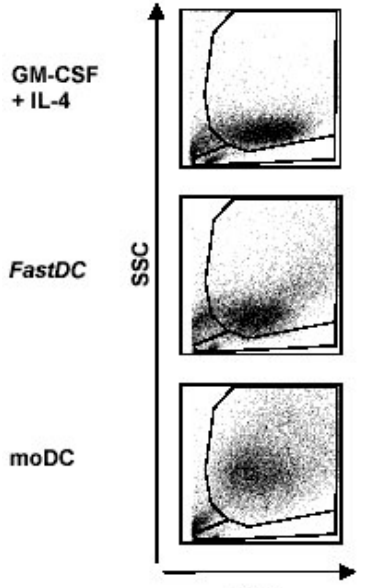

FSC

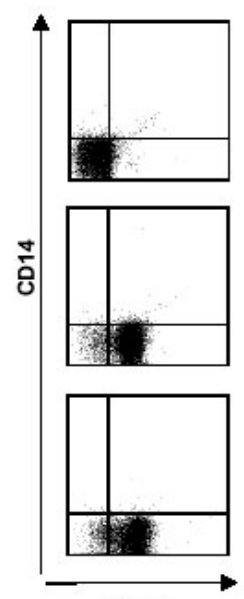

CD83

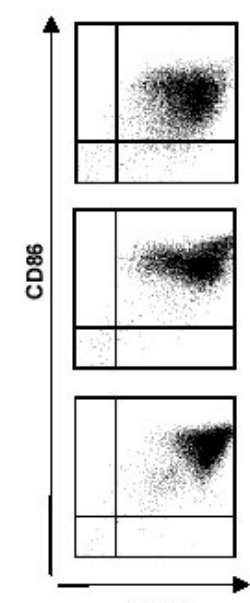

MHCII
Fig. 3: FastDC express equal levels of mature DC surface markers compared to standard monocyte-derived DCs (moDCs). Monocytes were cultured for 48 hours with GM-CSF plus IL-4 alone (top) or stimulated with proinflammatory mediators for the last 24 hours (middle). Expression of mature DC surface markers was compared with standard moDCs (bottom): monocytes were incubated with GM-CSF/IL-4 for 6 days followed by stimulation with proinflammatory mediators for another 2 days. Results of a representative FACS analysis out of five independent experiments are shown.

FastDC were similar to monocytes in size, but developed fine cytoplasmic protrusions. In contrast, moDCs had long cytoplasmic veils and showed considerable increase in size (data not shown). FSC/SSC analysis confirmed the light microscopy findings (Fig. 3). Compared to cells incubated with GM-CSF plus IL-4 alone, stimulated FastDC showed increased FSC/SSC intensity; moDCs showed an even greater increase in FSC/SSC intensity. Next, we assessed the expression of activation markers on all three cell-types by FACS analysis. As described above, cells incubated with GM-CSF plus IL-4 alone downregulate CD 14 and express moderate levels of CD86 and MHCII (Fig. 3, top). Stimulated FastDC displayed fully mature DC immunophenotype $\left(\mathrm{CD}_{3}{ }^{+} \mathrm{CD} 14-\mathrm{CD} 86^{\text {high }} \mathrm{MHCII}^{\text {high }}\right)$. The expression of activation markers was comparable to that of stimulated moDCs (Fig. 3, middle and bottom).

\section{Identification of proinflammatory mediators required for maturation of FastDC}

Having established a reliable protocol to generate mature dendritic cells from monocytes within 48 hours, we wanted to identify the proinflammatory mediators required for optimal maturation of FastDC. To this end, we compared stimulation with four proinflammatory mediators (IL-6, IL-1 $\beta$, TNF- $\alpha$ and $\mathrm{PGE}_{2}$ ) to stimulation with each of the proinflammatory mediators alone or stimulation with soluble CD40L trimer.

CD $14^{+}$cells were incubated with GM-CSF plus IL-4 for 24 hours followed by 24 hours of stimulation. After 48 hours we examined expression of mature DC surface markers and secretion of total IL-12. We discovered that none of the proinflammatory mediators could induce DC maturation if used alone: cells did not express CD83, they only upregulated CD86 and MHCII and they did not secrete IL-12. Only stimulation with $\mathrm{PGE}_{2}$ induced expression of the costimulatory molecules CD86 and MHCII to levels similar to those of FastDC (Fig. 4).
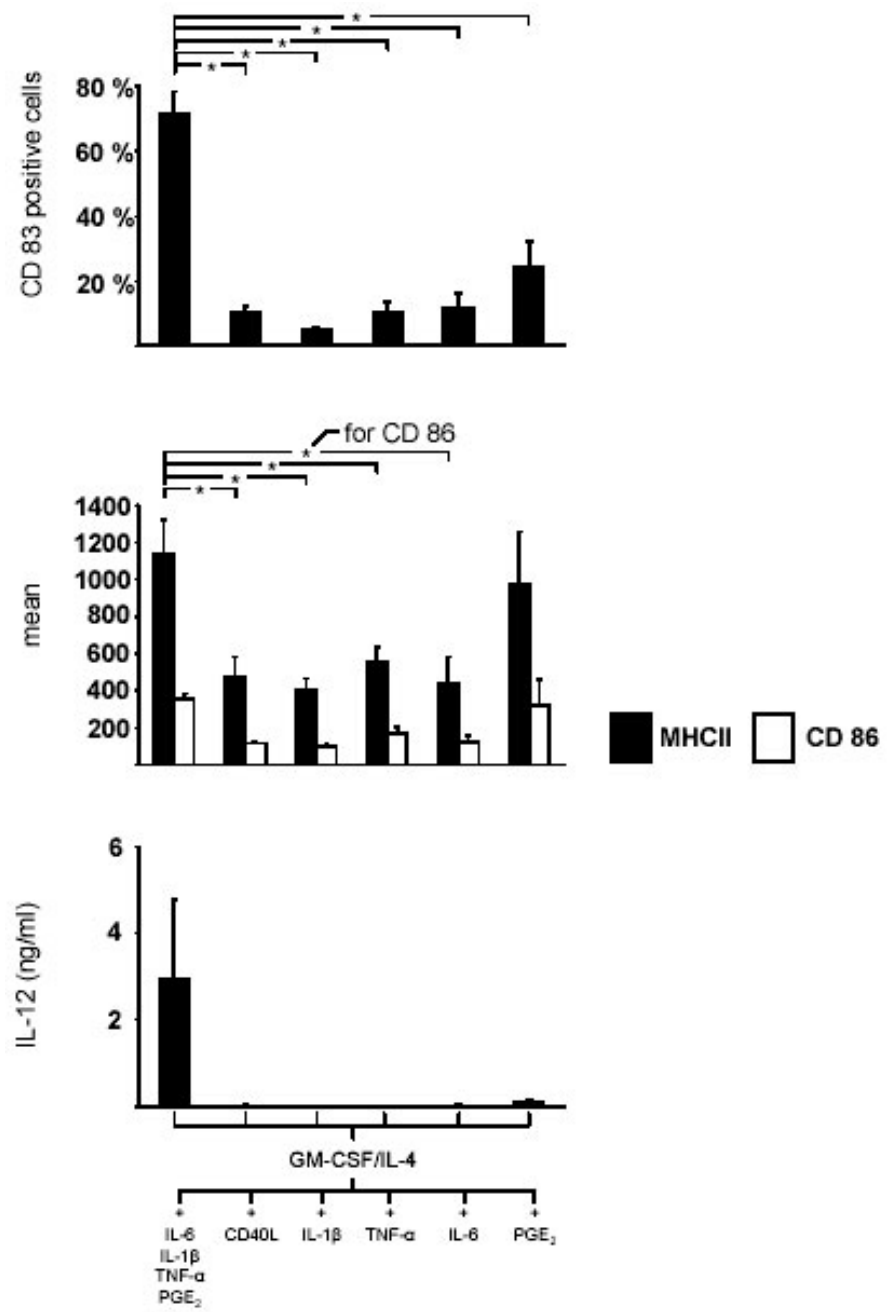

Fig. 4: A combination of four proinflammatory mediators is required for full maturation of FastDC. Monocytes were cultured with GM-CSF plus IL-4 for 48 hours and stimulated with either the combination of all four proinflammatory mediators or with each of the mediators alone or with soluble CD40L trimer for the last 24 hours. Expression of mature DC surface markers was determined by FACS (top) and culture supernatants were harvested for measurement of total IL-12 (IL-12 (p40) and IL-12 (p70), bottom). Data represent means \pm SEM of four experiments with different donors.

Our findings are supported by prior studies having shown that only a combination of different proinflammatory mediators effectively induces DC maturation (11-13).

\section{Functionality of FastDC}

The ability to take up antigen is characteristic for immature DCs and is lost upon stimulation (4). To determine their endocytic capacity, monocytes were cultured with GM-CSF and IL-4 for 48 hours and incubated with FITC-conjugated dextran at different time points: at the initiation of culture, after 12, 24 and 48 hours of culture. After 2 hours of incubation at $37^{\circ} \mathrm{C}$ cells were washed 
and dextran-uptake was measured by FACS analysis. Continuous increase in the uptake of FITC-dextran could be observed. After 24 hours cells already showed 10-fold increase in dextran-uptake (14). These findings suggest that monocytes incubated with GMCSF and IL-4 possess endocytic capacity and can be loaded with antigen. Upon maturation, endocytic capacity is rapidly lost (data not shown).

A characteristic of mature DCs is their ability to effectively stimulate $\mathrm{T}$ cell responses. To assess the capacity of FastDC to induce antigen-specific $\mathrm{T}$ cell responses, FastDC were loaded with tetanus toxoid protein (TT) as a model antigen (Protocol 3). TT-loaded FastDC were cocultured with autologous $\mathrm{T}$ cells in the presence of CD40Ligand. Cocultures with unloaded FastDC and with monocytes cultured with GM-CSF and IL-4 were used as controls. After 5 days, antigen-specific proliferation of autologous $\mathrm{T}$ cells cocultured with TT-loaded FastDC could be detected in a $\left(\mathrm{H}^{3}\right)$-thymidine proliferation assay (14). In an additional set of experiments, $\mathrm{T}$ cells were restimulated with the different cell types at day 10 of the coculture. After 4 hours of restimulation coculture supernatants were harvested for the measurement of IFN- $\gamma$ by ELISA. Only antigen loaded FastDC could induce a $\mathrm{T}_{\mathrm{H}} 1$ type immune response with high levels of IFN- $\gamma(14)$.

\section{Advantages of FastDC}

Taken together, our experiments demonstrate that mature DCs can be generated from monocytes within 48 hours. FastDC display a fully mature DC immunophenotype $\left(\mathrm{CD} 83^{+} \mathrm{CD} 14^{-}\right.$ CD86 ${ }^{\text {high }} \mathrm{MHCII}^{\text {high }}$ ) comparable to that of standard moDCs. Within the first 24 hours, monocytes incubated with GM-CSF and IL-4 display high endocytic capacity and can thus be effectively loaded with antigen. Compared to traditional protocols, generation of FastDC offers considerable advantages: the short period of in vitro culture (48 hours) not only reduces labor, cost and time but also renders cells less sensitive for external disruptive factors. Moreover, we found a greater reliability in the expression of surface markers on FastDC ( $>$ $90 \% \mathrm{CD}_{3}{ }^{+}$) and a greater stability and yield of mature DCs (up to $50 \%$ of the initial population of monocytes) compared to a standard protocol of 7 days.

\section{Yield and stability of FastDC}

For our experiments, we only used moncytes freshly isolated from PBMCs. MACS-purification proved to be superior to plastic adherence concerning purity and yield of isolated monocytes (purity $>95 \%$ vs. 80-90\%). After MACS purification, the yield of monocytes was at least twice as high as after plastic adherence. From $100 \mathrm{ml}$ of peripheral blood the average yield of monocytes by MACS was 25 million compared to 9 million by plastic adherence. Although a number of studies have shown significant differences between DCs generated from monocytes isolated by MACS or plastic adherence, we did not observe any differences concerning phenotype and function of FastDC. In both cases, up to $50 \%$ of the initial population of monocytes could be recovered after 48 hours.

To evaluate stability of FastDC, we cultured fully mature FastDC in the absence of cytokines. Monocytes were incubated with GMCSF and IL-4 and stimulated for the last 24 hours of culture with proinflammatory mediators. After a total culture period of 48 hours, FastDC were harvested, washed and cultured in complete medium without addition of cytokines or growth factors. Expression of mature DC surface markers remained stable for 48 hours after removal of cytokines (data not shown).

\section{ACKNOWLEDGMENTS}

This work is part of the doctoral thesis of B. Obermaier at the Ludwig-Maximilians-University, Munich, Germany. M. Dauer is supported by a grant of the University of Munich FöFoLe No. 271 and by a grant of the Friedrich-Baur-Stiftung, Munich. We thank Rosemarie Kiefl for technical assistance.

\section{REFERENCES}

1. Banchereau J, Briere F, Caux C, Davoust J, Lebecque S, Liu YJ, Pulendran B, Palucka K. Immunobiology of dendritic cells. Annu Rev Immunol 2000; 18:767-811.

2. Cella M, Engering A, Pinet V, Pieters J, Lanzavecchia A. Inflammatory stimuli induce accumulation of MHC class II complexes on dendritic cells. Nature 1997; 388:782-787.

3. Schnurr M, Then F, Galambos P, Scholz C, Siegmund B, Endres S, Eigler A. Extracellular ATP and TNF-alpha synergize in the activation and maturation of human dendritic cells. J Immunol 2000; 165:4704-4709.

4. Sallusto F, Lanzavecchia A. Efficient presentation of soluble antigen by cultured human dendritic cells is maintained by granulocyte/macrophage colony-stimulating factor plus interleukin 4 and downregulated by tumor necrosis factor alpha. J Exp Med 1994; 179:1109-1118.

5. Romani N, Gruner S, Brang D, Kampgen E, Lenz A, Trockenbacher B, Konwalinka G, Fritsch PO, Steinman RM, Schuler G. Proliferating dendritic cell progenitors in human blood. J Exp Med 1994; 180:83-93.

6. Randolph GJ, Beaulieu S, Lebecque S, Steinman RM, Muller WA. Differentiation of monocytes into dendritic cells in a model of transendothelial trafficking. Science 1998; 282:480483.

7. Czerniecki BJ, Carter C, Rivoltini L, Koski GK, Kim HI, Weng DE, Roros GJ, Hijazi YM, Shuwen X, Rosenberg SA, Cohen PA. Calcium ionophore-treated peripheral blood monocytes and dendritic cells rapidly display characteristics of activated dendritic cells. J Immunol 1997; 159:3823-3837.

8. Faries MB, Bedrosian I, Xu S, Koski G, Roros JG, Moise MA, Nguyen HQ, Engels FH, Cohen PA, Czerniecki B. Calcium signaling inhibits interleukin-12 production and activates CD83(+) dendritic cells that induce Th2 cell development. Blood 2001; 98:2489-2497. 
9. Schnurr M, Galambos P, Scholz C, Then F, Dauer M, Endres S, Eigler A. Tumor cell lysate-pulsed human dendritic cells induce a $T$-cell response against pancreatic carcinoma cells: an in vitro model for the assessment of tumor vaccines. Cancer Res 2001; 61:6445-6450.

10. Palucka KA, Taquet N, Sanchez-Chapuis F, Gluckman JC. Dendritic cells as the terminal stage of monocyte differentiation. J Immunol 1998; 160:4587-4595.

11. Jonuleit H, Kuhn U, Muller G, Steinbrink K, Paragnik L, Schmitt E, Knop J, Enk EH. Pro-inflammatory cytokines and prostaglandins induce maturation of potent immunostimulatory dendritic cells under fetal calf serumfree conditions. Eur J Immunol 1997; 27:3135-3142.

12. Feuerstein B, Berger TG, Maczek C, Roder C, Schreiner D, Hirsch U, Haendle I, Leisgang W, Glaser A, Kuss O, Diepgen TL, Schuler G, Schuler-Thurner B. A method for the production of cryopreserved aliquots of antigenpreloaded, mature dendritic cells ready for clinical use. $J$ Immunol Methods 2000; 245:15-29.

13. Snijders A, Kalinski P, Hilkens CM, Kapsenberg ML. Highlevel IL-12 production by human dendritic cells requires two signals. Int Immunol 1998; 10:1593-1598.

14. Dauer M, Obermaier B, Herten J, Haerle C, Pohl K, Rothenfusser S, Schnurr M, Endres S, Eigler A. Mature dendritic cells derived from human monocytes within 48 hours: a novel strategy for dendritic cell differentiation from blood precursors. J Immunol 2003; 170:4069-4076.

15. Santini SM, Lapenta C, Logozzi M, Parlato S, Spada M, Di Pucchio T, Belardelli F. Type I inteferon as a powerful adjuvant for monocyte derived dendritic cell development and activity in vitro and Hu-PBL-SCID mice. J Exp Med 2000; 191:1777-1788. 


\section{PROTOCOLS}

\section{Equipment}

$50 \mathrm{ml}$ pp-tubes (Greiner Bio-one GmbH, Frickenhausen, Germany)

$550 \mathrm{ml}\left(175 \mathrm{~cm}^{2}\right)$ tissue culture flasks with filter (Greiner Bio-one GmbH, Frickenhausen, Germany)

Cell scraper (Sarstedt AG \& Co, Nümbrecht, Germany)

Tissue culture plates, 6 well, flat-bottom (Becton Dickinson Falcon, Heidelberg, Germany)

\section{Reagents and medium (see Materials \& Methods)}

\section{Protocol 1: Isolation of monocytes}

1. Prepare medium for the culture of human PBMC: supplement $500 \mathrm{ml}$ RPMI medium with $2 \%$ human AB serum, $2 \mathrm{mM} \mathrm{L}$ glutamine, $50 \mathrm{U} / \mathrm{ml}$ penicillin and $50 \mu \mathrm{g} / \mathrm{ml}$ streptomycin (complete medium).

2. Full blood must be gained from volunteer healthy donors by venous punction.

3. Dilute the full heparinized (50 I.E Heparin $/ \mathrm{ml}$ blood) blood with $0.9 \%$ sodium chloride in a ratio of 1:2.

4. Stratify $30 \mathrm{ml}$ of the diluted blood on $15 \mathrm{ml}$ of Ficoll-Hypaque (Biochrom, Berlin, Germany) in a $50 \mathrm{ml} \mathrm{pp}$-tube.

5. Centrifuge cells for 20 minutes at a temperature of $20^{\circ} \mathrm{C}$ and a speed of $1000 \mathrm{~g}$.

6. After centrifugation a ring of PBMC gets visible in the interphase between Ficoll-Hypaque and the serum. Transfer the PBMC into a new $50 \mathrm{ml}$ pp-tube by using a pipette. To wash the cells add sodium chloride up to the $45 \mathrm{ml}$ mark of the tube.

7. Centrifuge the cells for 15 minutes at a temperature of $20^{\circ} \mathrm{C}$ and a speed of $520 \mathrm{~g}$.

8. To purify PBMC wash the cells twice in sodium chloride $(0.9 \%)$ and centrifuge cells for 10 minutes at a temperature of $4^{\circ} \mathrm{C}$ and a speed of 300g.

9. Now either use the MACS CD14 isolation kit according to the manufacturer's instruction to isolate monocytes or keep to the following instructions: resuspend the PBMC in complete medium. Resuspend cells isolated out of $50 \mathrm{ml}$ of full blood in $20 \mathrm{ml}$ of complete medium and transfer them into a $550 \mathrm{ml}$ tissue culture flask.

10. Let the cells adhere for one hour in the incubator $\left(37^{\circ} \mathrm{C}\right.$ and $\left.5 \% \mathrm{CO}_{2}\right)$.

11. After one hour control the cells microscopically and remove the non-adherent cell fraction. You can keep it for coculture experiments. To increase purity of the adherent monocytes rinse the culture flask twice with warm PBS.

12. Add $20 \mathrm{ml}$ of fresh warm complete medium to the adherent cell fraction and incubate the cells for $24 \mathrm{~h}$ at $37^{\circ} \mathrm{C}$ and $5 \% \mathrm{CO}_{2}$.

13. After 24 hours the initially adherent monocytes come off and can be harvested. To optimize results use the cell scraper and rinse the culture flask twice with PBS.

14. Centrifuge cells for 10 minutes at a temperature of $4^{\circ} \mathrm{C}$ and a speed of $300 \mathrm{~g}$.

15. Count the monocytes and resuspend them in complete medium at a concentration of 0.75 to 1.5 million cells per ml.

\section{Protocol 2: Generation of FastDC from monocytes in vitro}

1. After isolation (either by MACS (purity $>95 \%$ ) or by collecting the plastic adherent fraction (purity 80-90\%) of PBMC) resuspend monocytes in complete medium at a concentration of 0,75 to 1,5 million cells per ml. After MACS purification the yield of monocytes was at least twice as high compared to plastic adherence (average yield from $100 \mathrm{ml}$ of peripheral blood: MACS, 25 million monocytes; plastic adherence, 9 million monocytes).

2. Before culturing the monocytes you always should screen their morphology and purity by FACS analysis.

3. Plate monocytes in a 6 well tissue culture plate at a density of 1.5 to 3 million cells per dish in $2 \mathrm{ml}$ of medium.

4. Add $500 \mathrm{U} / \mathrm{ml} \mathrm{IL}-4$ and $1000 \mathrm{U} / \mathrm{ml}$ GM-CSF to the cell suspension.

5. Incubate the cells for 24 hours at $37^{\circ} \mathrm{C}$ and $5 \% \mathrm{CO}_{2}$.

6. After 24 hours add a cocktail of proinflammatory mediators to the cell suspension: $1000 \mathrm{U} / \mathrm{ml} \mathrm{TNF}-\alpha, 10 \mathrm{ng} / \mathrm{ml} \mathrm{IL}-1 \beta, 10 \mathrm{ng} / \mathrm{ml}$ IL-6 plus $1 \mu \mathrm{M}$ PGE$_{2}$.

7. Incubate the cells again for 24 hours at $37^{\circ} \mathrm{C}$ and $5 \% \mathrm{CO}_{2}$.

8. After a total culture period of 48 hours harvest the dendritic cells (FastDC).

\section{Protocol 3: Antigen-loading of FastDC}

1. Resuspend monocytes in complete medium at a concentration of 0.75 to 1.5 million cells per $\mathrm{ml}$ and plate monocytes in a 6 well tissue culture plate at a density of 1.5 to 3 million cells per dish in $2 \mathrm{ml}$ of medium.

2. Add $500 \mathrm{U} / \mathrm{ml} \mathrm{IL-4}$ and $1000 \mathrm{U} / \mathrm{ml} \mathrm{GM-CSF}$ to the cell suspension.

3. Add the antigen to the cell suspension.

4. After 24 hours of incubation with the antigen add a cocktail of proinflammatory mediators to the cell suspension to induce DC maturation: $1000 \mathrm{U} / \mathrm{ml}$ TNF- $\alpha, 10 \mathrm{ng} / \mathrm{ml}$ IL-1 $\beta, 10 \mathrm{ng} / \mathrm{ml}$ IL-6 plus $1 \mu \mathrm{M}$ PGE$_{2}$.

5. Incubate the cells again for 24 hours at $37^{\circ} \mathrm{C}$ and $5 \% \mathrm{CO}_{2}$ and harvest them after a total culture period of 48 hours. 